\title{
Association of Creatinine Clearance Rate and Coronary Angiographic Severity in Patients with Coronary Artery Disease
}

\author{
Mofazzal Hossain ${ }^{1}$, HI Lutfur Rahman Khan², Abdul Wadud Chowdhury²,Abu Sadique Abdullah ${ }^{3}$, \\ Md. Gaffar Amin², Mohammad Sarwar Alam, SM Eftar Jahan Kabir ${ }^{4}$, Tunaggina Afrin \\ Khan $^{5}$,Chowdhury Omar Faruk ${ }^{6}$ \\ ${ }^{1}$ Upazila Health Complex, Basail, Tangail, ${ }^{2}$ Department of Cardiology, Dhaka Medical College, Dhaka, \\ ${ }^{3}$ Department of Cardiology, Bangabandhu Sheikh Mujib Medical University, Dhaka, ${ }^{4}$ Department of \\ Cardiology, National Institute of Cardiovascular Diseases, Dhaka, ${ }^{5}$ Department of Cardiology, \\ Anowar Khan Modern Medical College \& Hospital, ${ }^{6}$ Emergency Department, MAG Osmani Medical \\ College, Sylhet
}

Key Words:
Creatinine
clearance rate.
Ischaemic heart
disease, Coronary
angiographic
severity.

\begin{abstract}
:
Background: In epidemiological studies and clinical trials renal function has been shown to be an independent predictor of coronary artery disease (CAD). We conducted this study to find out the association between creatinine clearance rate $(\mathrm{CCr})$ and coronary angiographic severity in patients with (CAD).

Method: It was a cross sectional study carried out in the department of Cardiology, Dhaka Medical College Hospital, Dhaka during the period of April, 2011 to March, 2012. All the patients with Ischaemic heart disease (IHD) admitted in the department of Cardiology who fulfill the inclusion and exclusion criteria and underwent coronary angiogram were taken as sampling population. Sampling technique was purposive and sample size was 118. By Cockcroft-Gault formula, CCr was estimated from serum creatinine. Coronary angiographic severity of coronary artery disease was assessed by vessel score and stenosis score. Statistical analysis was carried out by descriptive statistics, correlation coefficient test and one way ANOVA test. Level of significance was set at 0.05.

Results: Mean CCr among study subjects was $72.57 \pm 17.78 \mathrm{ml} / \mathrm{min}$. Vessel score showed $18.6 \%$ had normal coronaries, $37.3 \%$ single vessel disease, 31.4\% double vessel disease and $12.7 \%$ triple vessel disease. There was significant positive relationship between serum creatinine and vessel score, and also negative relationship between CCr and vessel score. The study also showed significant negative correlation between $\mathrm{CCr}$ and stenosis score.

Conclusion: Angiographic severity of coronary artery disease is associated with degree of renal dysfunction. Decreased creatinine clearance is associated with more extensive CAD.
\end{abstract}

(Cardiovasc. j. 2015; 7(2): 108-113)

\section{Introduction:}

Cardiovascular diseases are presently the leading causes of death in industrialized countries and expected to become so in developing countries by $2020 .{ }^{1}$ Atherosclerotic coronary heart disease (CHD) remains the leading cause of death in the developed world. ${ }^{2}$ Various studies have pointed out that South Asians have a higher prevalence of coronary artery disease (CAD) as compared with other ethnicities. ${ }^{3,4}$ Renal function, as measured by serum creatinine, blood urea nitrogen, or estimated creatinine clearance, has been shown in epidemiological studies and clinical trials to be an independent predictor of CAD. ${ }^{5-9}$ Mild renal impairment is associated with an increased risk of coronary artery disease and stroke, suggesting that cardiovascular disease may develop early in the course of renal dysfunction. ${ }^{10}$ Increased serum creatinine concentration may reflect generalized vascular disease denoting early nephrovasculopathy in association with established atherosclerotic risk factors. ${ }^{9,11,12}$ Serum creatinine is commonly used to estimate renal function but is a poor predictor of glomerular filtration rate. Glomerular filtration rate is the ideal test for determining kidney function, but it

Address of Correspondence: Dr. Mofazzal Hossain, Upazila Health Complex, Basail, Tangail, Bangladesh. email: mofazzaltushar@yahoo.com 
is difficult to measure. For practical purposes, estimated creatinine clearance is used as a correlate of glomerular filtration rate and is commonly estimated by using the Cockcroft-Gault formula without the need for 24 hour urine collection. ${ }^{13-15}$

\section{Methods:}

It was a cross sectional study carried out in the department of Cardiology, Dhaka Medical College Hospital (DMCH), Dhaka during the period of April, 2011 to March, 2012. All the patients with Ischemic heart disease (IHD) admitted in the Department of Cardiology, DMCH, Dhaka within the study period who fulfill the inclusion and exclusion criteria and underwent CAG in the Department of Cardiology, DMCH were taken as sampling population. Patients having previous PCI or CABG, serious co-morbid conditions such as severe renal dysfunction or ESRD, hepatic dysfunction, malignancy, systemic infection and unwilling to give consent were excluded from the study. Sampling technique was purposive and sample size was 118. Informed consent was taken from each patient or from legal guardian. Initial evaluation of patients was performed by history and clinical examination. Baseline investigations e.g. serum lipid profile, ECG, echocardiography were done for each patient. Serum creatinine was measured before CAG. By Cockcroft-Gault formula $\mathrm{CCr}$ was estimated and categorized as normal $(>90$ $\mathrm{ml} / \mathrm{min}$ ), or mild renal dysfunction $(\mathrm{CCr}>60 \mathrm{ml} /$ min.), moderate renal dysfunction (CCr $30-60 \mathrm{ml} /$ min.) and severe renal dysfunction $(\mathrm{CCr}<30 \mathrm{ml} /$ min.). ${ }^{14,15}$ Coronary angiogram was done in all patients who fulfill the inclusion and exclusion criteria. Interpretations of CAG were done by at least two cardiologists blinded to each other. Angiographic severity of coronary artery disease was assessed by vessel score (0-3 points for 0-3 vessels with coronary artery disease), and stenosis score(0-3 points: number and severity of coronary stenoses or lesions; 0 for no, 1 for coronary lesion with diameter stenosis less than $50 \%, 2$ for $50 \%-75 \%$, and 3 for more than $75 \%$ diameter stenosis). Data were analyzed by using SPSS (Statistical Package for the Social Science) version 16 . Test statistics used to analyze the data were descriptive statistics, correlation coefficient and one way ANOVA test. Level of significance was set at 0.05 .

\section{Results:}

One hundred eighteen patients with IHD, admitted in the department of Cardiology, DMCH in the study period were enrolled in the study. Creatinine clearance rate $(\mathrm{CCr})$ was calculated from serum creatinine by using Cockcroft-Gault formula. ${ }^{15}$ Patients with severe renal dysfunction and end stage renal disease (ESRD) were excluded from the study. The mean \pm SD age of the total patients was $50.99 \pm 9.25$ years ranging from 30 to $70 \mathrm{yr}$. Male (83.9\%) were more than the female (16.1\%) patients. By diagnosis, $30.5 \%$ patients had acute MI (STEMI/NSTEMI), 26.3\% had stable angina, $28.8 \%$ old MI and $14.4 \%$ unstable angina.

Table I shows the distribution of traditional risk factors of the study subjects. Dyslipidaemia was found to be the most common risk factor and obesity was least common.

\section{Table-I}

Distribution of traditional risk factors among the study subjects $(n=118)$.

\begin{tabular}{lc}
\hline Traditional risk factors & No. of patients \\
\hline Smoking & $51(43.2 \%)$ \\
Hypertension & $60(50.8 \%)$ \\
Diabetes mellitus & $36(30.5 \%)$ \\
Dyslipidaemia & $95(80.5 \%)$ \\
F/O premature CAD & $11(9.3 \%)$ \\
Obesity & $9(7.6 \%)$ \\
\hline
\end{tabular}

Table II shows that there was wide range of creatinine clearance rate $(\mathrm{CCr})$ among study subjects with mean $\pm \mathrm{SD}$ of $72.57 \pm 17.78 \mathrm{ml} / \mathrm{min}$.

Table-II

Serum creatinine level and creatinine clearance rate $(C C r)$ among study subjects $(n=118)$.

\begin{tabular}{lcc}
\hline Parameter & Range & Mean \pm SD \\
\hline Serum creatinine $(\mathrm{mg} / \mathrm{dl})$ & $0.61-1.90$ & $1.05 \pm 0.24$ \\
$\mathrm{CCr}(\mathrm{ml} / \mathrm{min})$. & $37.50-129.82$ & $72.57 \pm 17.78$ \\
\hline
\end{tabular}

Table III shows biochemical parameters of the study subjects. The mean \pm SD of random blood sugar (RBS) was $7.20 \pm 2.64 \mathrm{mmol} / \mathrm{L}$. The lipid profile analysis showed that main feature of dyslipidemia was high triglyceride (TG)

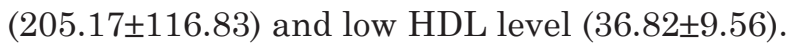
Fig 1 shows that majority had either single vessel disease (37.3\%) or double vessel disease (31.4\%). 
Table-III

Biochemical parameters of the study subjects $(n=118)$.

\begin{tabular}{lcc}
\hline Parameter & Range & Mean \pm SD \\
\hline $\begin{array}{l}\text { Random blood sugar } \\
(\mathrm{mmol} / \mathrm{L})\end{array}$ & $3.12-14.40$ & $7.20 \pm 2.64$ \\
Total Cholesterol (mg/dl) & $105-276$ & $184.52 \pm 34.73$ \\
$\begin{array}{l}\text { High density lipoprotein } \\
(\mathrm{mg} / \mathrm{dl})\end{array}$ & $17-83$ & $36.82 \pm 9.56$ \\
$\begin{array}{l}\text { Low density lipoprotein } \\
\text { (mg/dl) }\end{array}$ & $38-211$ & $109.71 \pm 36.60$ \\
Triglyceride (mg/dl) & $30-577$ & $205.17 \pm 116.83$ \\
\hline
\end{tabular}

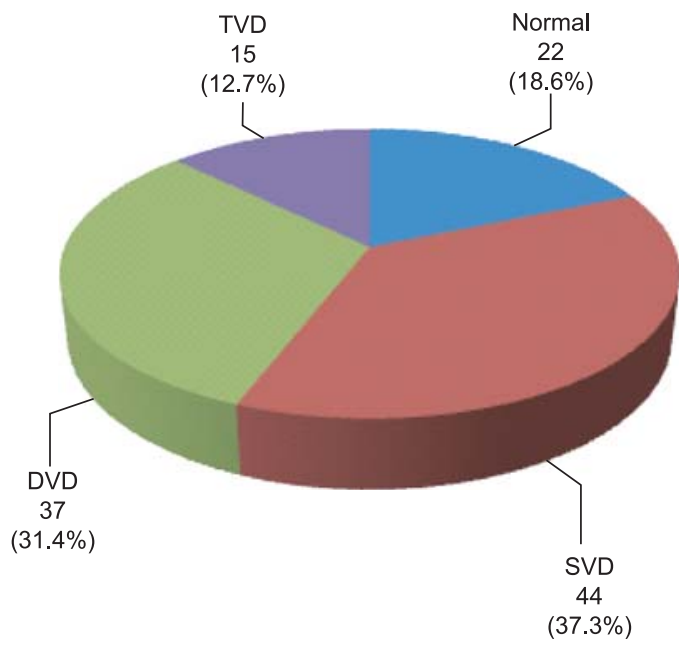

Fig.-1: Pie diagram showing distribution of study subjects by vessel score $(n=118)$.

Table IV shows that vessel score 0 or normal coronaries had lowest mean $\pm \mathrm{SD}$ of serum creatinine and vessel score 3 or triple vessel disease had highest mean \pm SD of serum creatinine. There was significant relationship between serum creatinine and vessel score $(p=0.022)$.

\section{Table-IV}

Distribution of vessel score by serum creatinine

$$
(n=118) \text {. }
$$

\begin{tabular}{lccc}
\hline $\begin{array}{l}\text { Vessel } \\
\text { score }\end{array}$ & $\begin{array}{c}\text { No.of }(\%) \\
\text { patients }\end{array}$ & $\begin{array}{c}\text { Mean } \pm \text { SD } \\
(\mathrm{mg} / \mathrm{dl})\end{array}$ & P value \\
\hline 0 & $22(18.6 \%)$ & $0.96 \pm 0.11$ & 0.022 \\
1 & $44(37.3 \%)$ & $1.02 \pm 0.20$ & \\
2 & $37(31.4 \%)$ & $1.09 \pm 0.30$ & \\
3 & $15(12.7 \%)$ & $1.19 \pm 0.28$ & \\
\hline
\end{tabular}

$\mathrm{P}$ value is derived from one way ANOVA test
Table V shows that vessel score 0 or normal coronaries had highest mean $\pm \mathrm{SD}$ of creatinine clearance rate $(\mathrm{CCr})$ and vessel score 3 or triple vessel disease had lowest mean $\pm \mathrm{SD}$ of creatinine clearance rate $(\mathrm{CCr})$. There was significant relationship between creatinine clearance rate $(\mathrm{CCr})$ and vessel score $(\mathrm{p}=0.011)$.

\section{Table-V}

Distribution of vessel score by creatinine clearance rate $(\mathrm{CCr})(n=118)$.

\begin{tabular}{lccc}
\hline $\begin{array}{l}\text { Vessel } \\
\text { score }\end{array}$ & $\begin{array}{c}\text { No.of }(\%) \\
\text { patients }\end{array}$ & $\begin{array}{c}\text { Mean } \pm \text { SD } \\
(\mathrm{mg} / \mathrm{dl})\end{array}$ & P value \\
\hline 0 & $22(18.6)$ & $81.75 \pm 16.33$ & 0.011 \\
1 & $44(37.3)$ & $72.45 \pm 13.39$ & \\
2 & $37(31.4)$ & $71.34 \pm 22.30$ & \\
3 & $15(12.7)$ & $62.46 \pm 12.85$ & \\
\hline \multicolumn{4}{l}{ P value is derived from one way ANOVA test }
\end{tabular}

Fig 2 shows that there was negative correlation between creatinine clearance rate and stenosis score $\left(r=-0.353^{* *}\right)$ and that was significant $(p<0.001)$. So, the less the creatinine clearance rate the more the stenosis score.

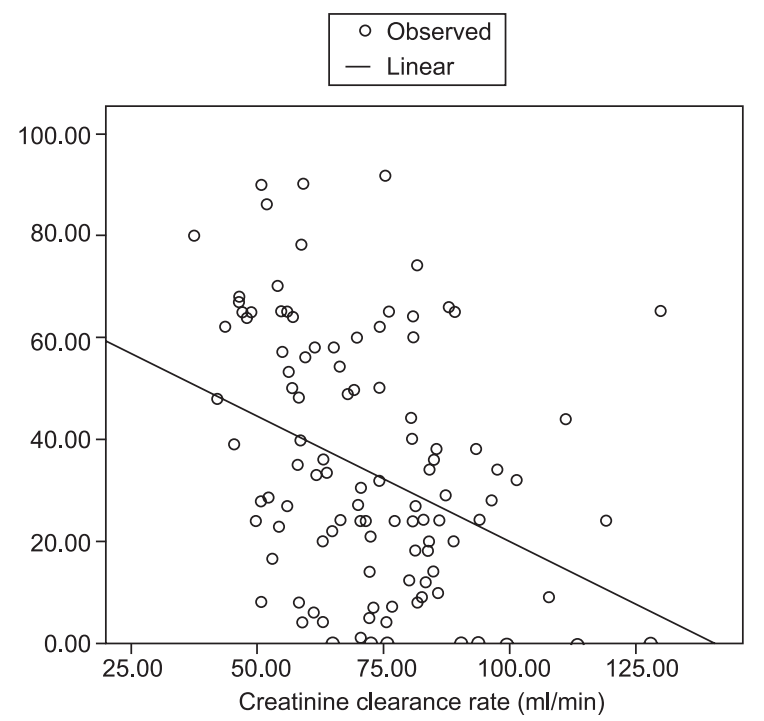

Fig.-2: Scattered plot showing negative correlation between creatinine clearance rate and stenosis score $(n=118)$

\section{Discussion:}

The presence of an altered renal function in essential hypertension, advanced heart failure (HF) and after a myocardial infarction (MI) is associated with higher cardiovascular morbidity and 
mortality. Indices of altered renal function (e.g., microalbuminuria, increased serum creatinine concentrations, decrease in estimated creatinine clearance or overt proteinuria) are independent predictors of cardiovascular morbidity and mortality. ${ }^{14}$

Cardiovascular mortality is profoundly affected by the presence of advanced renal failure. In patients undergoing maintenance hemodialysis, cardiovascular mortality is approximately 3 to 20 times that of age-matched non uremic control subjects. ${ }^{14}$ The increased mortality is associated with a higher frequency of conditions such as myocardial infarction (MI), left ventricular hypertrophy $(\mathrm{LVH})$, and congestive heart failure (CHF). Hypervolemia, arterial hypertension, and dyslipidaemia are among the most relevant causes leading to increased cardiovascular morbidity and mortality in advanced renal failure. ${ }^{14}$ Renal function is a major determinant of cardiovascular outcome in patients with essential hypertension or with heart failure (HF) in the absence of primary renal disease. A minor increase in serum creatinine above normal values and, conversely, a slight decrease in creatinine clearance were powerful predictors of future cardiovascular death. ${ }^{14}$

A prospective multicentre observational study, GRACE (Global Registry of Acute Coronary Events) was conducted by Santopinto, et al. to determine whether creatinine clearance at the time of hospital admission is an independent predictor of hospital mortality and adverse outcomes in patients with acute coronary syndromes (ACS). ${ }^{16} 11,774$ patients hospitalized with ACS, including ST and non-ST segment elevation acute myocardial infarction and unstable angina were enrolled in the study. The study revealed that patients with moderate or severe renal dysfunction were older, were more likely to be women, and presented to participating hospitals with more co-morbidities than those with normal or minimally impaired renal function. In comparison with patients with normal or minimally impaired renal function, patients with moderate renal dysfunction were twice as likely to die and those with severe renal dysfunction almost four times more likely to die after adjustment for other potentially confounding variables. The risk of major bleeding episodes increased as renal function worsened. ${ }^{16}$
In another study, Holzmann, et al. included six thousand seven hundred eleven consecutive patients without dialysis dependent renal insufficiency undergoing a first isolated coronary artery bypass grafting. ${ }^{17}$ There were 136 early deaths. After adjustment for age and other confounders in multivariate analyses, moderate (calculated creatinine clearance $30-60 \mathrm{~mL} / \mathrm{min}$ ) and severe (calculated creatinine clearance d" 30 $\mathrm{mL} / \mathrm{min}$ ) renal insufficiency predicted early mortality [odds ratio of 2.4 (95\% confidence interval, 1.2-4.8) and odds ratio of 4.8 (95\% confidence interval), 1.6-13.9, respectively] compared with normal (calculated creatinine clearance e"90 mL/ min) renal function. No increased risk of mediastinitis or bleeding was observed in patients with renal insufficiency. The authors concluded that moderate and severe renal insufficiency independently increase the risk of early death after coronary artery bypass grafting. Results also indicate that calculated creatinine clearance is a better predictor of early mortality postoperatively than serum creatinine concentration. ${ }^{17}$

In the present study, mean $\pm \mathrm{SD}$ of serum creatinine of study subjects was $1.05 \pm 0.24 \mathrm{mg} / \mathrm{dl}$ and mean \pm SD of CCr was $72.57 \pm 17.78 \mathrm{ml} / \mathrm{min}$. Out of total 118 patients, 22 (18.6\%), 44(37.3\%), 37 (31.4\%) and 15 (12.7\%) had coronary angiographic normal coronaries, single vessel disease, double vessel disease and triple vessel disease respectively. Patients with normal coronaries had lowest serum creatinine level and highest creatinine clearance rate $(\mathrm{CCr})$. In contrast, patients with triple vessel disease had highest serum creatinine and lowest CCr. There was significant positive relationship between vessel score and serum creatinine. The mean creatinine level of triple vessel disease patients was $1.19 \pm$ 0.28 whereas that of double \& single vessel disease patients was $1.09 \pm 0.30 \& 1.02 \pm 0.20$ respectively $(p=0.022)$. There was also significant negative relationship between vessel score and CCr. Single vessel disease patients had mean CCR 72.45 \pm 13.39 whereas double \& triple vessel disease patients had mean CCR $71.34 \pm 22.30 \& 62.46 \pm 12.85$ respectively $(p=0.011)$.

So, the present study revealed that redued $\mathrm{CCr}$ is associated with increased vessel score and stenosis score. It indicates that the less the $\mathrm{CCr}$, the more 
the vessel score and stenosis score i.e. more the renal dysfunction, more the extensive CAD. Our findings are consistent with the findings of Reis, et al. ${ }^{18}$

Reis et al. studied 728 women with normal renal function (creatinine $\leq 1.2 \mathrm{mg} / \mathrm{dL}$ ) and 56 with mild renal insufficiency (creatinine 1.2 to $1.9 \mathrm{mg} / \mathrm{dL}$ ). All women had chest pain and underwent quantitative coronary angiography. ${ }^{16}$ Creatinine correlated with angiographic CAD severity score $(p<0.05)$ and maximum coronary artery stenosis $(p=0.003)$. Compared with women with normal renal function, those with mild renal insufficiency were more likely to have significant angiographic CAD ( $\geq 50 \%$ diameter stenosis in $\geq 1$ coronary artery) $(61 \%$ versus $37 \%$; $<<0.05)$ and $\mathrm{CAD}$ in multiple vessels ( $\mathrm{p} \leq 0.05$ for association) and had greater maximum percent diameter coronary stenosis $(59 \pm 35 \%$ versus $38 \pm 36 \%$; $<<0.05)$. Mild renal insufficiency was associated with significant angiographic $\mathrm{CAD}$ independent of age and risk factors $(\mathrm{OR}=1.9,95 \% \mathrm{CI}=1.1$ to 3.5$)$. They concluded that in women with chest pain, mild renal insufficiency is an independent predictor of significant angiographic CAD. Mildly increased serum creatinine is probably a marker for unmeasured proatherogenic factors. ${ }^{16}$

In Turkey Korkmaz et al. ${ }^{19}$ reviewed 892 consecutive patients with typical stable angina pectoris and showed that those in the highest creatinine group ( $\geq 1.5 \mathrm{mg} / \mathrm{dl}$, but not above $3 \mathrm{mg} /$ dl) had the highest total stenosis score $(17 \pm 6$, $\mathrm{p}<0.05)$ and extension score $(78 \pm 25, \mathrm{p}<0.05)$ irrespective of age and gender. ${ }^{19}$ Creatinine was shown to be significantly correlated with both stenosis and extension scores. ${ }^{19}$

In this study, vessel score and stenosis score, which are parameters of angiographic severity of $\mathrm{CAD}$, had progressive increasing association with progressively decreasing renal function that is indicated by CCr. So, angiographic severity of coronary artery disease (CAD) is inversely related to $\mathrm{CCr}$ level.

\section{Conclusion:}

The present study concludes that angiographic severity of coronary artery disease is associated with degree of renal dysfunction. That is, angiographic severity of coronary artery disease
(CAD) is inversely related to creatinine clearance level.

\section{Conflict of Interest - None.}

\section{References:}

1. Murray, C.J. Lopez, A.D. Alternative projections of mortality and disability by cause 1990-2020: Global Burden of Disease Study. Lancet 1997; 349: 1498-1504.

2. Assmann, G. Schulte, H. Relation of high-density lipoprotein cholesterol and triglyceride to incidence of atherosclerotic coronary artery disease (the PROCAM experience). Prospective Cardiovascular Munster Study.Am J Cardiol 1992; 70: 733-737.

3. Manninen, V. Tenkanen, L. Koskinen, P. et al. Joint effects of serum triglyceride and LDL cholesterol and HDL cholesterol on coronary heart disease risk in the Helsinki Heart Study: Implications for treatment. Circulation 1992; 85: 37-45.

4. Hanak, V. Munoz, J. Teague, J. et al. Accuracy of the triglyceride to high-density lipoprotein cholesterol ratio for prediction of low-density lipoprotein phenotype B. Am J Cardiol 2004; 94: 219-222.

5. Wannnamethee, S.G. Shaper, Perry, I.J. Serum creatinine concentration and risk of cardiovascular disease: A possible marker for increased risk of stroke. Stroke 1997; 28: 557-563.

6. Alcorn, H.G. Wolfson, S.K.Jr. Sutton-Tyrrell, K. et al. Risk for abdominal aortic aneurysm in older adults enrolled in the cardiovascular health study. Arterioscler Thromb Vasc Biol 1996; 16: 963-970.

7. Gottlieb, S.S. Mc Carter, R.J. vogel, R.A. Effect of betablockade on mortality among high risk and low risk patients after myocardial infarction. N Engl J Med 1998; 339: 489-497.

8. Pahor, M. Shorr, R.I. Somes, G.W. et al. Diuretic-based treatment and cardiovascular events in patients with mild renal dysfunction enrolled in the systolic hypertension in the elderly program. Arch Intern Med 1998; 158: 1340-1345.

9. Culleton, B.F. Larson, M.G. Wilson, P.W. Evans, J.C. Perfrey, P.S. and Levy, D. Cardiovascular disease and mortality in a community-based cohort with mild renal insufficiency. Kidney Int 1999a; 56: 2214-2219.

10. Landry, M.J. Thambyrajah, J. McGlynn, F. J. Jones, H.J. Baigent, C. Kendall, M.J. Townend, J.N. Wheeler, D.C. Epidemiological evaluation of known and suspected cardiovascular risk factors in chronic renal impairment. Am J Kidney Dis 2001; 38: 537-546.

11. Cerne, D. Kaplan-Pavlovcic, S. Kranjec, I. et al. Mildly elevated serum creatinine concentration correlates with the extent of coronary atherosclerosis. Ren Fail 2000; 22: 799-808. 
12. Culleton, B.F. Larson, M.G. Evans, J.C. Wilson, P.W.F. Barrett, B.J. Parfrey, P.S. and Levy, D. Prevalence and correlates of elevated serum creatinine levels: the Framingham Heart Study. Arch Intern Med 1999b; 159: 1785-1790.

13. Levy, A.S. Controlling the epidemic of cardiovascular disease in chronic renal disease: where do we start? Am J Kidney Dis 1998; 32: S5-13.

14. Ruilope, L.M. van Veldhuisen, D.J. Ritz, E. et al. Renal function: the cinderella of cardiovascular risk profile. $J$ Am Coll Cardiol 2001; 38: 1782-1787.

15. Cockcroft, D. W. Gault, M.H. Prediction of creatinine clearance from serum creatinine. Nephron 1976; 16: 31-41.

16. Santopinto, J.J. Fox, K.A.A. Goldberg, R.J. Budaj, A. Pinero, G. Avezum, A et al. on the behalf of the GRACE investigators. Creatinine clearance and the adverse hospital outcomes in patients with acute coronary syndromes: findings from global registry of acute coronary events (GRACE). Heart 2003; 89: 1003-1008.

17. Holzmann, M.J. Ahnve, S. Hammar, N. Jorgensen, L. Klerdal, K. Pehrsson, K. and Ivert, T. Creatinine clearance and risk of early mortality in patients undergoing coronary artery bypass grafting. $J$ Thorac Cardiovasc Surg 2005; 130: 746-752.

18. Reis, S.E. Olson, M.B. Fried, L. Reeser, V. Mankad, S. Pepine, C,J. et al. Mild Renal Insufficiency Is Associated With Angiographic Coronary Artery Disease in Women. Circulation 2002; 105: 2826-2829.

19. Korkmaz S, Demirkan B, Altay H, RefikerM , Çaldýr V, Yýlmaz M.B, Güray Y, Güray U, Papmaz H. Serum creatinine is independently associated with angiographic extent of coronary artery disease in patients with stable angina pectoris. Anadolu Kardiyol Derg 2011; 11: 407-413. 